\title{
VIDEOFLUOROSCOPY: the gold standard exam for studying swallowing and its dysfunction
}

Costa MMB. Videofluoroscopy: the gold standard exam for studying swallowing and its dysfunction. Arq Gastroenterol. 2010;47(4): 327-8. HEADINGS - Cineradiography. Deglutition.

Videofluoroscopy is the standard exam for evaluating swallowing dynamics. Nevertheless, a number of other methodologies are also used. In this current edition of ARQUIVOS de GASTROENTEROLOGIA two insightful manuscripts entitled Clinical evaluation of oropharyngeal dysphagia in Machado-Joseph disease $^{(2)}$ and Effect of age on proximal esophageal response to swallowing ${ }^{(8)}$ utilizes other methodologies. The authors of the first study classified their results based on dysphagia severity scale, which was created with videofluoroscopy and they adopted cervical auscultation for the clinical evaluation of the pharyngeal phase of deglutition. Certainly, videofluoroscopy would allow to confirm and to give more reliability of the results.

The second manuscript utilized flux manometry with flawless methodology to study the upper, proximal segment of the esophagus, like the pharynx, is composed of striated muscle. This region is different of the distal esophagus, which is composed of smooth muscle. The contractility of the proximal third of the esophagus is determined by motor unit depolarization, like the pharynx. In this study, the manometric results allowed the authors to propose that older subjects had less effective upper esophageal contractions than younger subjects; they concluded that age may affect the response of the proximal esophagus to wet swallows. The observed outcomes may have been due to subclinical dysfunction in the oral and/or pharyngeal deglutition phases, which would only be detected by videofluoroscopy.

Videofluoroscopy is considered the gold standard method in studying swallowing and its dysfunction. Nevertheless, in Brazil, this technique remains underutilized. Many physicians do not know much about it, while others consider X-ray necessary, and still others use less effective methods due to their accessibility. Very frequently, it comes to our attention that many practitioners and health plans companies do not know the method; they have never heard of it, and often ask: "video what?" The good news is that videofluoroscopy of swallowing, as videodeglutogram, now has a Brazilian Medical Association (AMB) codification number (4.08.06.02-2).

Videofluoroscopy of swallowing is the process of recording dynamic deglutition events using X-ray and storing this information in magnetic media. The method enables high resolution real-time recording at 30 frames/ sec, which enables not only the morphological analyses, but also the physiological evaluation. The events can be viewed and reviewed, without new exposures. Being able to visualize the region frame by frame and/or in slow motion constitute the clear advantages of the video recording method ${ }^{(4,14)}$.

Lower kerma-area product rates (radiation exposure) and better image quality are currently available ${ }^{(5,6)}$. As previously mentioned, videofluoroscopy is universally accepted as the gold standard for studies on swallowing and its disorders ${ }^{(1,10,12,13)}$. The oral cavity can be analyzed for chewing, oral bolus organization and oral ejection. The pharynx can be analyzed for the form, the transit, palate competence and protection of airways. The esophagus can be analyzed for the lumen, the walls, the transit times and sphincteric competence $^{(9,10,11)}$.

Dynamic images are critical for swallowing studies. For this reason, difficult cervical anatomy, complex pharyngeal physiology and even pharyngeal cannot be understood as difficulties in videofluoroscopic interpretation. Many morphofunctional concepts can be reviewed on the videofluoroscopic study of swallowing, and much more can be learned with this method. Currently, it is already considered essential for the diagnosis and follow-up of dysphagia ${ }^{(3,12)}$.

Dysphagia, which can be a symptom of multiple diseases, is commonly a disease of multiple etiologies ${ }^{(7)}$. Its diagnosis and therapy require multi-disciplinary competence. Frequently, its etiology is neurological, but many other causes exist. In this way, many others competences complement the necessary knowledge of dysphagia, including neurologists, radiologists, clinical practitioners, surgeons, otorhinolaryngologists, gastroenterologists, pneumologists, nutrologists, pediatricians, nurses, speech pathologists, nutritionists and others. It is necessary that all of these professionals 
become aware of the importance of videofluoroscopy and that they disclose, learn, engage and practice the method.

We are an aging society. Cases of dysphagia are increasing. Videofluoroscopy allows for an appropriate diagnosis and guides the treatment, which would otherwise be empirically approached and guided by trial and error. The videofluoroscopic exam allow us to identify sub-clinical alterations and establish the most commonly compromised regions, classifying dysphagia as oral, pharyngeal, oral and pharyngeal or esophagic. Videofluoroscopy also permits clinical classification of dysphagia intensity as discrete, moderate or severe.
The method is relatively simple, the materials are inexpensive, and the regularly utilized equipment is available at most clinical centers and hospitals. The adaptation for dynamic imaging recording is technically easy and simple to implement ${ }^{(5)}$.

Universalization of the videofluoroscopic method is almost obligatory. With this method, we will be able to provide proper care for those patients assisted by the public health system and those patients with health insurance or health plans, who otherwise become socially excluded, disabled, suffer and die from malnutrition and/or pneumonia.

Milton Melciades Barbosa COSTA*

Costa MMB. Videofluoroscopia: o método padrão-ouro para o estudo da deglutição e sua disfunção. Arq Gastroenterol. 2010;47(4):327-8.

HEADINGS - Cinerradiografia. Deglutição.

\section{REFERENCES}

1. Beck TJ, Gayler BW. Image quality and radiation levels in videofluoroscopy for swallowing studies: a review. Dysphagia. 1990;5:118-28.

2. Corrêa SMA, Felix VN, Gurgel JL, Sallum RAA, Cecconello I. Clinical evaluation of oropharyngeal dysphagia in Machado-Joseph disease. Arq Gastroenterol. 2010;47:334-8

3. Costa MM, Koch HA. Lateral laryngopharyngeal diverticulum: anatomical and videofluoroscopic study. Eur Radiol. 2005;15:1319-25.

4. Costa MMB, Leocadio JL, Carlos MT, Pereira AA, Koch HA. Videofluoroscopia: um novo método. Radiol Bras. 1992;25:11-8.

5. Costa MMB, Canevaro LV, Koch HA, DeBonis R. Cadeira especial para o estudo videofluoroscópico da deglutição e suas disfunções. Radiol Bras. 2009;42:179-84.

6. Costa MMB, Nova JLL, Canevaro LV. Efeito da filtração adicional nas doses de radiação e na qualidade das imagens nos exames videofluoroscópicos. Radiol Bras. 2009;42:379-87.

7. Costa MMB. Videofluoroscopy: a radiological method indispensable for medical practice. Radiol Bras. 2010;43:vii-viii.

8. Dantas RO, Alves LMT, Dalmazo J, Sanots CM, Cassiane RA, Nascimento WV.
Effect age on proximal esophageal response to swallowing. Arq Gastroenterol. 2010;47:339-43.

9. do Nascimento FA, Lemme EM, Costa MM. Esophageal diverticula: pathogenesis, clinical aspects and natural history. Dysphagia. 2006;21:198-205.

10. Gramigna GD. How to perform video-fluoroscopic swallowing studies. GI Motility Online 2006; doi:10.1038/gimo95. Available from: http://www.nature.com/ gimo/contents/pt1/full/gimo95.html\#top

11. Jou J, Radowsky J, Gangnon R, Sadowski E, Kays S, Hind J, Gaumnitz E, Taylor A, Robbins J. Esophageal clearance patterns in normal older adults as documented with videofluoroscopic esophagram. Gastroenterol Res Pract. 2009;2009:965062. Epub 2009 Sep 23.

12. Kellen PM, Becker DL, Reinhardt JM, Van Daele DJ. Computer-assisted assessment of hyoid bone motion from videofluoroscopic swallow studies. Dysphagia. 2009 Oct 24. Epub ahead print. doi: 10.1007/s00455-009-9261-9.

13. Noll SF, Bender CE, Nelson MC. Rehabilitation of patients with swallowing disorders. In: Braddom RL, editor. Physical medicine \& rehabilitation. 2nd ed. Philadelphia: WB Saunders; 2000; p.535-60.

14. Videofluoroscopy. A dictionary of nursing. Oxford University Press; 2008. Encyclopedia.com. [acessado em $1^{\circ}$ de dezembro de 2009]. Available from: http:// www.encyclopedia.com

\footnotetext{
* Laboratory of Digestive Motility and Videofluoroscopy, Instituto de Ciências Biomédicas, Universidade Federal do Rio de Janeiro, Rio de Janeiro, RJ, Brazil.
} 